SHORT REPORT

\title{
Hazardous drinkers in the accident and emergency department - who attends an appointment with the alcohol health worker?
}

\author{
R Patton, M Crawford, R Touquet
}

Emerg Med J 2005;22:722-723. doi: 10.1136/emj.2004.018952

\begin{abstract}
Aims: To identify factors that predict attendance at a brief assessment and referral session among patients identified as hazardous drinkers while being treated in an accident and emergency department.

Methods: Patients presenting to an accident and emergency department (AED) were screened using the Paddington Alcohol Test (PAT). All patients identified as hazardous drinkers were given written information and offered an appointment with an alcohol health worker (AHW) to discuss their drinking. Data was collected on patients' age, gender, presenting condition, and alcohol consumption. Binary logistic regression was used to identify variables that predicted attendance at the appointment with the AHW among those who accepted advice.

Results: Patients who attended the appointment were older than those who did not. Those who believed their attendance in the AED was related to alcohol were also more likely to receive brief intervention.

Conclusions: Clinicians should explore patients' perceptions of the link between their alcohol consumption and AED attendance, and where appropriate emphasise the potential association.
\end{abstract}

A recent review and meta-analysis of interventions for hazardous alcohol consumption among primary care patients concluded that brief interventions consistently outperform minimal interventions in terms of the proportion of hazardous drinkers reducing their alcohol intake at a 6 month follow-up. ${ }^{1}$ The authors defined minimal intervention as a unique session of advice lasting up to 5 minutes without emphasis on specific ways to reduce consumption; brief interventions lasted longer than 10 minutes and included comprehensive assessment and strategies to reduce consumption. At the Accident and Emergency Department (AED) of St Mary's hospital, London, patients are routinely screened using the Paddington Alcohol Test (PAT) ${ }^{2}$, and those identified as hazardous drinkers are offered advice. Previously we have reported on the importance of simple feedback $^{3}$ and on the factors that predicted hazardous drinkers' acceptance of written advice (minimal intervention) and an appointment to attend an assessment and referral session with an alcohol health worker (brief intervention). ${ }^{4}$ In this short report we examine the factors that predicted patients' attendance to the appointment other than the periodicity of the next appointment. If physicians are aware of the characteristics of both patient and presentation associated with successful exposure to brief interventions, this should enable them to employ appropriate strategies to promote maximal attendance to such sessions, with consequent benefits.

\section{PARTICIPANTS/METHODS/RESULTS}

As part of a randomised controlled trial reported elsewhere, ${ }^{5}$ of 599 patients identified as hazardous drinkers over a one year period, 298 were offered an appointment to attend a brief assessment and referral session. Of these, 94 (31.5\%) actually attended the AHW appointment.

Demographic and clinical characteristics of those who did and did not attend the appointment are presented in the table below. A logistic regression analysis compared the characteristics of patients who were offered an appointment with the AHW and those who actually attended this appointment. This analysis included age, gender, primary reason for presentation (based on triage notes), units of alcohol consumed, and acceptance that the AED visit was related to alcohol consumption. Increasing age (OR 1.035, 95\% CI 1.013 to 1.058 ) together with an acceptance that their visit to the department was alcohol related (OR 2.59, 95\% CI 1.31 to 5.15), predicted attendance to the AHW appointment. Patients who presented to the AED 'feeling unwell' were more likely to attend for follow-up $\left(\chi^{2}=4.32, \mathrm{df}=1\right.$, $\mathrm{p}<0.05$ ) than those presenting with any other complaint.

\section{COMMENT}

This third short report-in our trilogy on the pragmatic management of alcohol misuse in $\mathrm{AEDs}^{3}{ }^{4}$-emphasises the importance of a patient recognising the relationship between their alcohol consumption and their subsequent presentation to the AED; the establishment of a "teachable moment". Those who demonstrate such insight are almost three times as likely to attend an appointment. Clinicians should therefore ensure that they establish awareness regarding this issue for all patients identified as hazardous drinkers, and where appropriate endeavour to facilitate this association. Early referral for alcohol problems, as discussed by D'Onofrio et al, ${ }^{6}$ is associated with a reduction in alcohol related morbidity and mortality. It is of note that doctors' self-reported levels of alcohol consumption do not influence their screening rates for alcohol misuse. ${ }^{7}$

In the absence of other diagnostic criteria, patients who present to the AED following acute alcohol intoxication are classified as "unwell", such patients are best placed to make an association between their drinking and subsequent attendance. Often such patients are having difficulty in coping with life in general, recognise they need help and are therefore already contemplating change-for example, reducing their alcohol intake. ${ }^{8}$ Reasons why older patients are more likely to attend appointments are less clear. Our data

Abbreviations: AED, accident and emergency department; AHW, alcohol health worker; PAT, Paddington Alcohol Test 


\begin{tabular}{|c|c|c|c|c|}
\hline \multicolumn{2}{|l|}{$\mathrm{N}(\%)$} & $\begin{array}{l}\text { Aftended appointment } \\
\mathrm{N}=94(31.5)\end{array}$ & $\begin{array}{l}\text { Did not attend appointment } \\
\mathrm{N}=204 \text { (68.5) }\end{array}$ & Difference in proportion $(95 \% \mathrm{Cl})$ \\
\hline \multirow{4}{*}{\multicolumn{2}{|c|}{$\begin{array}{l}\text { Gender: male } \\
\text { Average units consumed during } \\
\text { drinking session } \\
\text { Believed initial AED attendance } \\
\text { related to drinking } \\
\text { Aftended AED in the previous } 6 \text { months }\end{array}$}} & \multirow{2}{*}{$\begin{array}{l}71(75.5) \\
21.6\end{array}$} & \multirow{2}{*}{$\begin{array}{l}159(77.9) \\
22.5\end{array}$} & $-2.4(-12.8$ to 8.0$)$ \\
\hline & & & & $-0.9(-4.5$ to 2.7$)$ \\
\hline & & $60(63.8)$ & $92(45.1)$ & $18.7(6.9 \text { to } 30.6)^{* *}$ \\
\hline & & $31(33.3)$ & $51(25.1)$ & $8.2(-3.1$ to 19.5$)$ \\
\hline & \multicolumn{2}{|c|}{ Specific presenting condition } & All other conditions & Difference in proportion $(95 \% \mathrm{Cl})$ \\
\hline \multirow{18}{*}{$\begin{array}{l}\text { Patients who } \\
\text { attended } \\
\text { appointment }\end{array}$} & Fall & $13(35.1)$ & $81(34.0)$ & $1.1(-12.3$ to 20.5$)$ \\
\hline & Collapse & $17(37.0)$ & $77(30.6)$ & $6.4(-8.7$ to 21.5$)$ \\
\hline & Head Injury & $3(14.3)$ & $91(32.9)$ & $-18.6(-34.5$ to -2.6$)$ \\
\hline & Assault & $6(25.0)$ & $88(32.1)$ & $-7.1(-25.3$ to 11.1$)$ \\
\hline & NSGI & $13(33.3)$ & 81 (31.3) & $2.0(-13.8$ to 17.9$)$ \\
\hline & Unwell & $22(44.0)$ & $72(29.0)$ & $15.0(0.1 \text { to } 29.8)^{*}$ \\
\hline & Psychiatric & $8(26.7)$ & $86(32.1)$ & $-5.4(-22.2$ to 11.4$)$ \\
\hline & Cardiac & $4(19.0)$ & $90(32.5)$ & $-13.4(-31.1$ to 4.2$)$ \\
\hline & Accident & $3(33.3)$ & $91(31.5)$ & $1.8(-29.4$ to 33.1$)$ \\
\hline & Other & $5(23.8)$ & $89(32.1)$ & $-8.3(-27.3$ to 10.7$)$ \\
\hline & \multicolumn{2}{|c|}{ Specific age range } & \multicolumn{2}{|l|}{ All other ages } \\
\hline & $18-20$ & $2(25.0)$ & $92(31.7)$ & $-6.7(-37.2$ to 23.8$)$ \\
\hline & $21-30$ & $13(23.2)$ & 81 (33.5) & $-10.3(-22.8$ to 2.3$)$ \\
\hline & $31-40$ & $21(28.1)$ & $73(32.6)$ & $-4.2(-16.2$ to 7.8$)$ \\
\hline & $41-50$ & $15(21.4)$ & $79(34.6)$ & $-13.2(-24.6 \text { to }-1.8)^{*}$ \\
\hline & $51-60$ & $22(45.8)$ & $72(28.8)$ & $17.0(1.9 \text { to } 32.2)^{*}$ \\
\hline & $61-70$ & $18(51.4)$ & $76(28.9)$ & $22.5(5.1 \text { to } 40.0)^{* *}$ \\
\hline & $71+$ & $3(50.0)$ & 91 (31.2) & $18.8(-21.5$ to 59.2$)$ \\
\hline
\end{tabular}

did not demonstrate a significant association between age and acceptance that alcohol consumption was related to presentation to the AED. It may be that over time patients become increasingly aware of their own mortality and therefore experience elevated levels of motivation to address this issue. Further research as to what motivates patients to attend brief interventions is needed to better facilitate staff to gain empathy with their patients, thereby making maximum use of 'the teachable moment'. Extraneous factors, such as the periodicity of the AHW appointment, are reported on separately. ${ }^{9}$

\section{ACKNOWLEDGEMENT}

We are very grateful to St Mary's Hospital AED staff for the data collection facilitating this trilogy of papers focusing on our pragmatic clinical practice for managing Alcohol misuse, especially to SHO teams 30,31 , and 32 .

Correspondence to: Robert Patton, National addiction Centre, 4 Windor Walk, Denmark Hill, London SE5 8AF, UK; r.patton@iop.kcl. ac.uk

Accepted for publication 6 October 2004

\section{REFERENCES}

1 Ballesteros J, Duffy JC, Querejeta I, et al. Efficacy of Brief Interventions for Hazardous Drinkers in Primary Care: Systematic Review and Meta-Analysis. Alcoholism: Clin Exp Res 2004;28:608-618.

2 Patton R, Hilton C, Crawford MJ, et al. The Paddington Alcohol Test: A Short Report. Alcohol \& Alcohol 2004;39:266-268.

3 Patton R, Crawford MJ, Touquet R. Impact of health consequences feedback on patients acceptance of advice about alcohol consumption. Emerg Med J 2003; 20:451-452.

4 Patton R, Crawford MJ, Touquet R. Hazardous drinkers in the accident and emergency department - Who accepts advice? Emerg Med J 2004;21:491-492.

5 Crawford MJ, Patton R, Touquet R, et al. Screening and referral for brief intervention of alcohol misusing patients in an Accident and Emergency Department: A pragmatic randomised controlled trial. The Lancet 2004;364:1334-1339.

6 D'Onofrio G, Bernstein E, Bernstein J, et al. Patients with Alcohol Problems in the Emergency Department, Part 2: Intervention and Referral. Acad Emerg Med 1998;5:1210-1217.

7 Huntley JS, Patton R, Touquet R. Attitudes towards alcohol of emergency department doctors trained in the detection of alcohol misuse. Ann R Coll Surg Engl 2004;86:329-333.

8 Bien TH, Miller WR, Tonigan JS. Brief interventions for alcohol problems: a review. Addiction 1993;88:315-336.

9 Williams S, Brown A, Patton R, et al. The half-life of the 'teachable moment' for alcohol misusing patients in the emergency department. Drug Alcohol Depend 2005;77(2):205-208. 